\title{
Recent Digital Technology Trends in Geoscience Teaching and Practice
}

Kellen L. Gunderson, R. Chadwick Holmes, Chevron Energy Technology Company, 1500 Louisiana Street, Houston, Texas, 77044, USA; Julie Loisel, Department of Geography, Texas A\&M University, Eller O\&M Building, Room 810, College Station, Texas 77843, USA

\begin{abstract}
Digital technology advances are rapidly altering the landscape of geoscience teaching and practice. Although geoscience has readily embraced new digital technologies in the past, the simultaneous emergence of innovations like open online courses and machine learning toolkits has greatly steepened the learning curve for geoscientists of all experience levels. Here, we discuss how these technologies are affecting the jobs of geoscience teachers and practitioners by highlighting a few technology-related trends in these areas. We also note the potential challenges of this new technological environment. A holistic view of digital technology trends can help geoscientists position themselves for success in a future where technological advancements will presumably continue to occur at an even more rapid pace.
\end{abstract}

\section{INTRODUCTION}

Digital advances have been transforming society for several decades, as exemplified by the advent and proliferation of prominent technologies like personal computers, the Internet, and smart phones. In just the past few years, there has also been a rapid expansion in cloud computing, high-performance computing, the Internet of things, massive open online courses (MOOCs), and machine learning (ML) (Fig. 1). These simultaneous changes have the potential to act as a force multiplier, creating even more rapid societal change than previous relatively isolated advances. Recent progress in artificial intelligence (AI), when coupled with advancements in high-performance computing and the proliferation of cloud storage, have brought powerful tools that were once accessible to only a few researchers with supercomputers within the grasp of everyday software developers. This acceleration in society's digital transformation has the potential to change every industry and field of study (Frey and Osborne, 2017), including geoscience. Here, we synthesize recent trends in digital technology applications to geoscience teaching and practice and discuss some challenges associated with the dynamically changing technological environment.

\section{DIGITAL TRENDS IN GEOSCIENCE TEACHING}

The digital technology trends in geoscience education can be grouped into two themes: (1) new information delivery methods in the classroom, in the field, and online; and (2) updated curriculum content that caters to state-of-the-art research and practice. Virtual field trips and augmented reality tools are increasing student exposure to field locations with reduced costs (De Paor, 2016). MOOCs are providing students with cost-effective, flexible education options to choose from, thereby competing with the classical higher-education campus life model (Deming et al., 2018).

The demand for more "digitally fluent" graduates has accelerated changes in geoscience curricula. Some schools now offer specialized computer programming courses and workshops, which often include robust statistical reviews. New majors, minors, and certificates, such as geographic information system (GIS) or data science, are emerging as alternatives to a traditional geoscience degree. Employers need graduates who can adapt to a quickly changing technological landscape. Geoscience educators must focus on providing well-rounded and up-to-date course content, with expanded opportunities to strengthen the technical competencies of their students.

\section{DIGITAL TRENDS IN GEOSCIENCE PRACTICE}

Many practical geoscience disciplines, like petroleum exploration, are trying to capitalize on improvements in $\mathrm{AI}$ and the vast quantities of available subsurface data. Petroleum geoscientists showed early interest in AI, leveraging their pattern recognition capabilities to help detect hydrocarbonassociated anomalies in seismic data (Widrow et al., 1994) and define facies based on log patterns (Neri, 1997). Broader adoption of AI technologies has only recently accelerated, in part due to university partnerships to tackle key technical challenges, business alignments with tech companies, and competitive crowd-sourcing to supplement in-house research and development.

Most of the ML applications in petroleum geoscience have focused on seismic interpretation. Seismic interpretation software packages have historically provided semiautomated tools like signal auto-trackers or interpolation and gridding routines. Newer approaches are utilizing ML to interpret faults (Zheng et al., 2014), define salt boundaries (Di et al., 2018), or delineate geobodies based on labeling routines (Alaudah and $\mathrm{Al}$ Regib, 2016). With the growing popularity of neural network solutions and access to high-performance computing resources, advances in image segmentation and classification routines are now setting the stage for interpretation as a full-volume machineassisted analysis.

\section{CHALLENGES AND CAUTIONS}

The incorporation of computational geoscience skills into academic curricula remains a major challenge. Additional resources are needed to train existing faculty in the newest technology and/or hire new faculty whose research uses emerging technologies. Advocating for the inclusion of rigorous computational geoscience courses that include programming elements, beginning in the undergraduate curriculum, seems imperative.

While online education has many advantages, one drawback is the potential loss of 

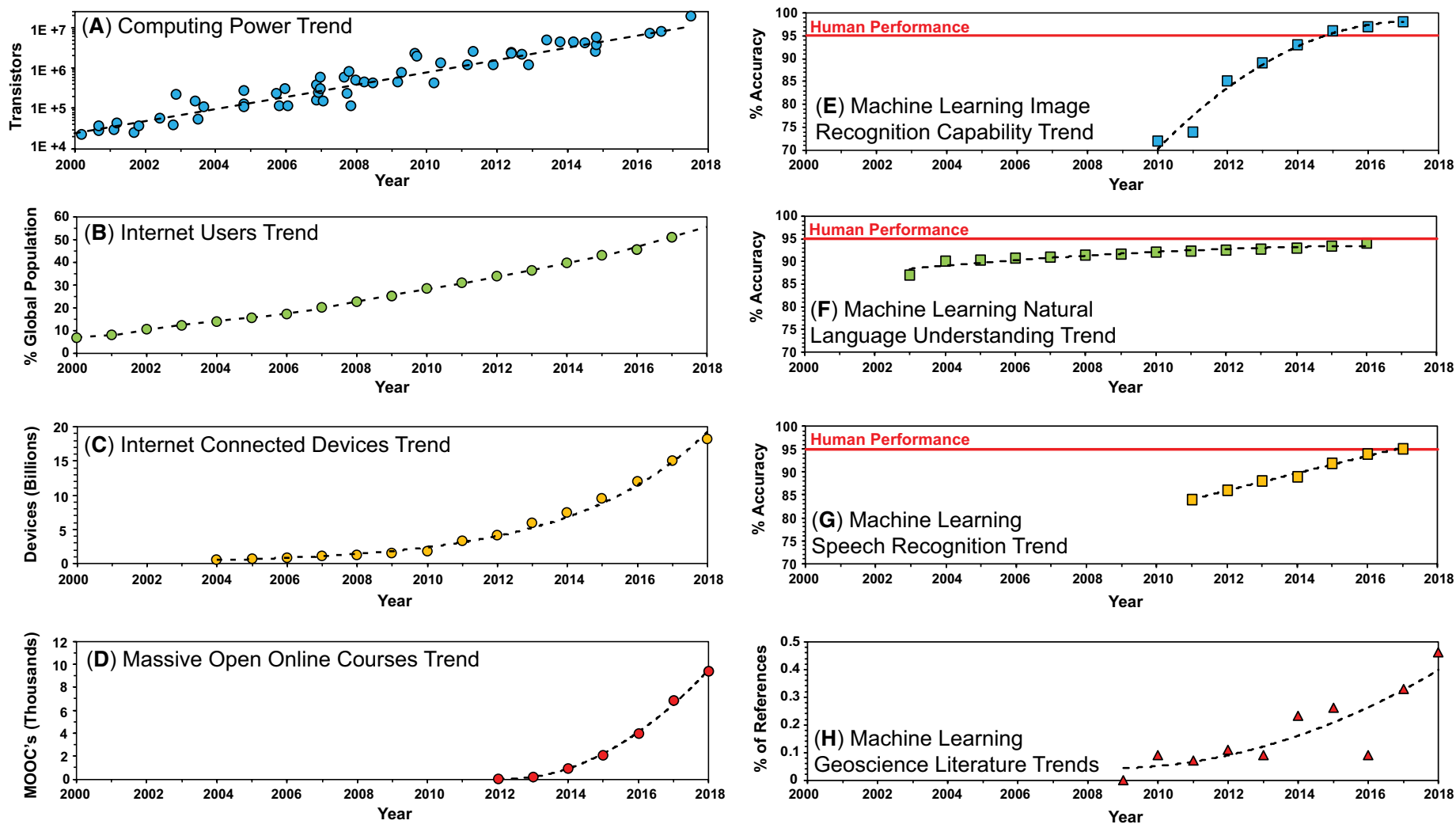

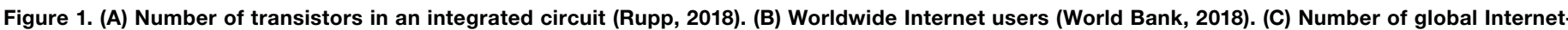

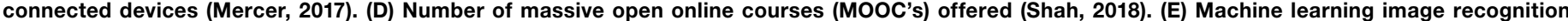

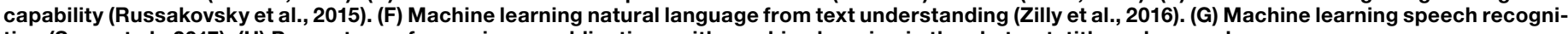
tion (Saon et al., 2017). (H) Percentage of geoscience publications with machine learning in the abstract, title, or keyword.

future students who become exposed to the geosciences through on-campus classes. General education geoscience courses, taught by passionate faculty and often supplemented with field trips, are an important tool to recruit new geoscience students. We think it is important that universities not lose their emphasis on field and lab work or their commitment to undergraduate research. These unique, high-impact learning experiences can only happen in person and are essential to mentoring students in our discipline.

Another point of caution is the potential erosion of key geoscience skills from an over-reliance on digital technology. This has been recognized as a potential risk in petroleum geology for more than a decade (Yeilding, 2005), as subsurface interpreters began to rely heavily on workstation-produced maps that often provide geologically unrealistic solutions. If virtual field trips and digital map-making become students' primary exposure to geologic mapping, the problem may grow even worse.

ML applications in geoscience present some unique challenges. Insufficient training data and poor experimental designs can lead to erroneous conclusions. Open-source data or black box algorithms used in an analysis may be of questionable quality. Until skilled geoscientists can "crack" the codes and truly understand algorithm mechanics and limitations, this problem will remain. In response, a growing number of journals are reinforcing new best practices, such as publishing codes and raw data. We assert that it is the role of the geoscience community to establish standard techniques and other best practices to solidify the correct use of popular new technologies.

\section{CONCLUSIONS}

The geoscientists that are most likely to thrive in this new technological environment are those willing to be agile and remain in a state of continuous learning. Maintaining static methods of teaching and practice will be insufficient. Paradoxically, despite the need for digital comprehension and capability, the most important functional knowledge and skills that any geoscientist should possess will likely remain the same. These include a deep understanding of fundamental Earth processes, an ability to creatively integrate data from various sources, the clarity to communicate difficult concepts, and a passion for their work. Technological dexterity will certainly bring additional value to our field, but we believe it will be the combination of deep fundamental geoscience knowledge and digital fluency that will be the foundation for the next era of geoscience innovation and discovery.

\section{ACKNOWLEDGMENTS}

We thank numerous colleagues for helpful discussions that informed the ideas in this paper. This manuscript was improved due to the helpful reviews by the GSA Today editor and an anonymous reviewer.

\section{REFERENCES CITED}

Alaudah, Y., and Al Regib, G., 2016, Weakly-supervised labeling of seismic volumes using reference exemplars: Image Processing (ICIP), Sept. 2016 IEEE International Conference, p. 4373-4377.

Deming, D.J., Lovenheim, M., and Patterson, R., 2018, The competitive effects of online education, in Hoxby, C.M., and Stange, K., eds., Productivity in Higher Education: Chicago, University of Chicago Press, $392 \mathrm{p}$

De Paor, D.G., 2016, Virtual rocks: GSA Today, v. 26 , no. 8 , p. $4-11$, https://doi.org/10.1130/ GSATG257A.1.

Di, H., Shafiq, M., and Al Regib, G., 2018, Multi-attribute k-means clustering for salt-boundary delineation from three-dimensional seismic data: Geophysical Journal International, v. 215 , no. 3 , p. 1999-2007, https://doi.org/10.1093/gji/ggy376. 
Frey, C.B., and Osborne, M.A., 2017, The future of employment: How susceptible are jobs to computerisation?: Technological Forecasting and Social Change, v. 114, p. 254-280, https://doi.org/10.1016/ j.techfore.2016.08.019.

Mercer, D., 2017, Smart Home Connected World: Smart Home Is Key to Tomorrow's Internet of Things: Strategy Analytics, https://www.strategy analytics.com/access-services/devices/connected -home/smart-home/reports (accessed Oct. 2018).

Neri, P., 1997, Revolutionary software for seismic analysis: World Oil, v. 218, no. 5, https://www.osti .gov/biblio/483881.

Rupp, K., 2018, 42 Years of Microprocessing Trend Data: https://www.karlrupp.net/2018/02/42-years -of-microprocessor-trend-data (accessed Oct. 2018).

Russakovsky, O., Deng, J., Su, H., Krause, J., Satheesh, S., Ma, S., Huang, Z., Karpathy, A., Khosla, A., Bernstein, M., Berg, A.C., and Fei-Feil, L., 2015, ImageNet Large Scale Visual Recogni- tion Challenge: International Journal of Computer Vision, v. 5, no. 211, https://doi.org/10.1007/ s11263-015-0816-y.

Saon, G., Kurata, G., Sercu, T., Audhkhasi, K., Thomas, S., Dimitriadis, D., Cui, X., Ramabhadran, B., Picheny, M., Lim., L., Roomi, B., and Hall, P., 2017, English conversational telephone speech recognition by humans and machines: arXiv preprint arXiv:1703.02136. https://arxiv.org/pdf/1703.02136.pdf (accessed Oct. 2018).

Shah, D., 2018, By the numbers: MOOC's in 2017: Class Central MOOC Report, https://www .class-central.com/report/mooc-stats-2017 (accessed Oct. 2018)

Widrow, B., Rumelhart, D.E., and Lehr, M.A., 1994, Neural networks: Applications in industry, business and science: Communications of the ACM, v. 37 , no. 3 , p. $93-105$, https://doi.org/10.1145/ 175247.175257.
World Bank, 2018, Individuals using the Internet (\% of population): https://data.worldbank.org/ indicator/IT.NET.USER.ZS (accessed Oct. 2018).

Yeilding, C., 2005, Is the workstation "killing" geology?: Houston Geological Society Bulletin, v. 47, no. 9, p. 27-29.

Zheng, Z.H., Kavousi, P., and Di, H.B., 2014, Multiattributes and neural network-based fault detection in 3D seismic interpretation: Advanced Materials Research, v. 838, p. 1497-1502.

Zilly, J.G., Srivastava, R.K., Koutník, J., and Schmidhuber, J., 2016, Recurrent highway networks: arXiv preprint arXiv:1607.03474, https://arxiv.org/pdf/ 1607.03474.pdf (accessed Oct. 2018).

ManusCript Received 2 Mar. 2019

Revised Manuscript ReCeived 4 SePt. 2019

ManusCript accepted 17 SePt. 2019 